\title{
QUOD TIBI FIERI NON VIS, ALTERI NE FECERIS: A CRÍTICA DE HABERMAS À REGRA DE OURO
}

\author{
DELAMAR JosÉ VolPATO Dutra
}

\begin{abstract}
The text presents Habermas' analysis and criticism of the role that the Golden Rule plays in Hobbes's system. According to Habermas, the golden rule suggests the kind of arguments that Hobbes would need to deduce the natural laws, which Hobbes intends to draw only from the interested perspective of the rational selfish ego. Next, the paper presents the same criticism to Rawls, but this time based on the analysis of the strategy of the original position. The paper concludes that the contractualist strategy of both thinkers import a cognitive deficit in the sense of being unable to account for the principles of justice based on equality and freedom, that is, on the impartial point of view that would serve the interest of all.
\end{abstract}

Keywords: Habermas; Hobbes; golden rule; Rawls; original position.

\section{Introdução}

De acordo com Rawls, "Hobbes's Leviathan is the greatest single work of political thought in the English language" (Rawls 2007, p.23). A grandeza de um autor pode ser medida pelas críticas que lhe são feitas, bem como pelo status dos nomes que o criticam. Dentre as muitas críticas que lhe foram endereçadas, como a de ser um positivista jurídico, duas são de particular relevo. Um primeiro conjunto delas pode ser agregado sob a denominação de déficit obrigacional. Essa crítica se refere ao vínculo que as normas portam em relação à vontade do sujeito que deve cumpri-las. Ela porta conexão com a estabilidade social, a qual também pode ser analisada mediante a relação entre teoria e prática. Pode-se considerar Kant como um dos primeiros críticos de Hobbes, nesse sentido, em seu texto Contra Hobbes. Alinham-se nesse viés também Nagel (1959), Rawls (2007) e Habermas (1971). Nesse sentido, as obras de Taylor (1938) e Warrender (1957) podem ser consideradas como uma tentativa de resposta a essa problemática. Uma segunda crítica se refere ao que se poderia chamar de déficit cognitivo presente no contratualismo de Hobbes. Essa é a principal objeção de Habermas (1994, cap. III) a Hobbes. Aliás, Habermas (1998, cap. 2) não só imputa essa crítica também a Rawls, como lhe acresce ainda aquela que este imputara a Hobbes, qual seja, a de que sua teoria seria portadora de um déficit obrigacional.

O presente estudo trata da crítica de Habermas a Hobbes.

Principia 20(3): 377-392 (2016).

Published by NEL — Epistemology and Logic Research Group, Federal University of Santa Catarina (UFSC), Brazil. 


\section{A regra de ouro em Hobbes}

O problema formulado por Hobbes é o da produção da ordem social a partir dos interesses dos indivíduos ou das partes que compõem a sociedade: "Na sua forma clássica, o problema hobbesiano tinha se colocado da forma seguinte: de que modo o encontro das perspectivas egocêntricas de indivíduos que agem no interesse próprio pode produzir uma ordem capaz de obrigar os atores individuais a levar em conta os interesses dos outros" (Habermas 1997b, p.78). Segundo Habermas, o ponto de partida de Hobbes diz respeito a "ações dirigidas por interesses de egoístas racionais ou, como diria Kant, de um 'povo de demônios"' (1997a, p.123). Isso significa uma atitude orientada para o sucesso no estado de natureza, com base na racionalidade estratégica. Esse ponto de partida Habermas o caracteriza como o da primeira pessoa do singular. Porém, esta não seria a perspectiva de análise para "trocar suas liberdades de ação naturais — conflitantes, porém ilimitadas — pelas liberdades do direito privado, isto é, as que são compatibilizadas e limitadas segundo leis gerais" (Habermas 1997a, p.124). Na verdade, duas condições seriam necessárias para fazer a transição do conflito à cooperação.

Em primeiro lugar seria necessário entender o que é um contrato. Todavia, para a compreensão da ideia de reciprocidade do contrato precisar-se-ia da perspectiva da segunda pessoa do singular, ou seja, as partes "teriam que poder compreender o significado geral de uma relação social apoiada no princípio da reciprocidade" (Habermas 1997a, p.124). Porém, eles não dispõem dessa cognição, pois a sua perspectiva no estado de natureza é aquela da primeira pessoa que atua estrategicamente, ou seja, eles

ainda não aprenderam, antes de qualquer socialização, a assumir a perspectiva de um outro e a considerar-se a si mesmos na perspectiva de uma segunda pessoa. Sem isso, sua própria liberdade é considerada simplesmente como uma liberdade que bate contra obstáculos fáticos, não podendo ser vista como uma liberdade constituída através do reconhecimento recíproco (Habermas 1997a, p.124).

Em segundo lugar, é necessário entender o contrato social. Para tal, precisa um afastamento ainda maior de si, pois implicaria um descentramento do eu capaz de assumir a primeira pessoa do plural, ou seja, as partes "teriam que poder assumir a perspectiva social de uma primeira pessoa no plural — que o autor Hobbes e seus leitores sempre assumiram tacitamente - , a qual, no entanto, está vedada aos sujeitos no estado natural" ((Habermas 1997a, p.125). Esse ponto de vista seria necessário para julgar da simetria e da reciprocidade das normas necessárias para se instituir uma ordem social aceitável por todos, ou seja, tratar-se-ia da possibilidade de conceber "se a reciprocidade da coerção, que limita o arbítrio de cada um segundo leis 
gerais, é do interesse simétrico de todos, podendo, por isso, ser querida por todos os participantes" (Habermas 1997a, p.125).

A regra de ouro, usada por Hobbes, alega Habermas, seria o reconhecimento do "tipo de argumentos morais que entram nesse jogo" (Habermas 1997a, p.125). Ora, é o próprio Hobbes quem confessa que a regra de ouro é a suma da lei natural. Ele a cita em sua forma negativa logo depois da segunda lei natural no cap. XIV do Leviathan. Cita-a, também, na sua forma positiva como resumo de todas as leis depois da décima nona lei de natureza no cap. XV e, novamente como resumo de todas as leis naturais, na sua forma negativa no cap. XXVI. Contudo, tais argumentos morais que a regra de outro introduz estariam em contradição com a sua perspectiva inicial de fundamentação de normas com base em um sistema do egoísmo bem ordenado, com fundamento no autointeresse esclarecido dos indivíduos.

Com isso, Habermas não quer dizer que a regra de ouro seja o modo mais acurado para se conseguir tais argumentos. Por isso, ele usa a expressão de que a regra de ouro aponta para a espécie de argumentos morais que seriam exigíveis para o caso:

\begin{abstract}
Hobbes reconheceu o tipo de argumentos morais que entram nesse jogo, nas passagens em que ele recorre à regra de ouro, tida como uma lei natural Quod tibi fieri non vis, alteri ne feceris. Porém, tal impregnação moral do estado natural está em contradição com os pressupostos naturalistas da prova que ele pretende atingir, a saber, fundamentar a construção de um sistema do egoísmo bem ordenado, a partir do autointeresse esclarecido de todos os indivíduos (Habermas 1997a, p.125).
\end{abstract}

Ou seja, tratar-se-ia de uma indicação da perspectiva de reciprocidade das regras, restando determinar ainda, amiúde, se a regra de ouro consegue operacionalizar tal perspectiva. Forçoso concluir, também, a partir dessa perspectiva, que Habermas interpreta as teorias da lei natural como sendo baseadas na moral, incluso a de Hobbes, o que ele sabidamente critica (Habermas 1997b, p.321). Vale a pena anotar que Habermas inclui também Kant e Rawls na tradição do direito natural moderno. Esses três filósofos constituem uma sólida tradição de tratamento do direito e da ordem social em relação à qual Habermas apresentará sua própria teoria discursiva do direito. Desse modo, parece que Habermas tem que ficar a meio caminho entre uma fundamentação contratualista, para ele insuficiente, e uma fundamentação moral, para ele também problemática. O que unificaria os três autores seria a conexão entre a explicação da ordem social, do direito e da moral, de tal forma que se operaria uma fundamentação moral do direito, o que ele imputa também a Hobbes, como se pode inferir da parte da referência anterior segundo a qual a regra de ouro seria uma espécie de confissão de que estariam a operar no argumento, sub-repticiamente, razões morais. Como dito, a regra de ouro sugeriria exatamente o tipo de argumento moral que seria necessário na explicação da ordem social, sem, contudo, conseguir ofertar tal argumento.

Principia 20(3): 377-392 (2016). 


\section{A crítica de Kant e Habermas à regra de ouro}

Habermas filia-se ao lado dos que aceitam a crítica kantiana à regra de ouro. Em nota ao texto da Fundamentação referente à formulação do imperativo categórico como ordem de tratar a humanidade sempre como fim, especificamente no caso dos deveres perfeitos para com os outros, Kant afirma que a regra de ouro, que ele cita apenas em sua formulação negativa, só pode ser entendida como derivada do imperativo categórico, não o contrário, e ainda assim com várias restrições:

Não se pense que o trivial: quod tibi non vis fieri etc. possa servir aqui de norma ou princípio. Pois ele é, se bem que com diversas restrições, tãosomente derivado daquele; não pode ser uma lei universal, visto que não contém o fundamento dos deveres para consigo mesmo, nem dos deveres do amor aos outros (pois muitos topariam de bom grado que os outros não lhes fizessem o bem desde que pudessem se dispensar de se mostrar benfazejos a eles), nem tampouco, por fim, dos deveres exigíveis de uns para com os outros; pois o criminoso argumentaria com base nisso contra o juiz que lhe dita uma pena, etc. (Kant 2009, p.430).

Kant não diz quais restrições seriam necessárias para tal derivação, contudo, ele parece sustentar que se a regra de ouro fosse tomada sem qualquer limitação, ela não fundamentaria nenhum tipo de dever, devido justamente à preponderância da perspectiva do eu. Segundo Rawls, o que Kant critica na regra de ouro é que ela permite que as inclinações e circunstâncias pessoais tenham um papel no raciocínio prático, o que não seria o caso com o imperativo categórico (Rawls 2000, p.199). No exemplo de Kant, o criminoso ao manejar a regra de ouro a partir do seu desejo de não ser punido, gera a conclusão de que ninguém quer ser punido e de que, portanto, ninguém pode punir porque também não quer ser punido. Por outro lado, a inconsistência que o não seguimento do imperativo categórico gera é mais radical do que a determinada pela regra de ouro, já que este não depende de tais particularidades, as quais, então, desempenham um papel impróprio na deliberação. ${ }^{1}$

Segundo Habermas, a regra de ouro tem um caráter egocêntrico que o imperativo categórico, em tese, não teria, contudo, se o imperativo categórico fosse operacionalizado de forma monológica, ele se aproximaria do caráter egocêntrico da regra de outro (2004, pp.70-1). Nesse particular, a rigor, para ele, nem o imperativo categórico é acurado o suficiente, haja vista a sua ética discursiva ser justamente uma reformulação do imperativo categórico (Volpato Dutra, 2002). A acusação por ele endereçada ao imperativo categórico é semelhante àquela que ele imputa a Rawls, como se verá.

Ora, o que ele acusa no neocontratualismo de Rawls é justamente ser uma perspectiva egocêntrica, a qual deve ser estendida também ao imperativo categórico, como ver-se-á a seguir. Deveras, a acurácia do posicionamento de Habermas, em re- 
lação ao contratualismo e à tradição moderna do direito natural, pode ser melhor vislumbrada na crítica que ele endereça ao neocontratualismo de Rawls, importando anotar que Habermas interpreta a teoria da justiça de Rawls como o retorno do direito natural moderno (Habermas 1997a, p.83).

Ora, Habermas critica justamente a interpretação contratualista do imperativo categórico, pois esta se constituiria exatamente na tentativa de dar uma estrutura empírica a tal imperativo, o que ocorreria pela posição original. A esse respeito, duas citações são importantes sobre a posição original: (a) "In justice as fairness the original position of equality corresponds to the state of nature in the traditional theory of the social contract" (Rawls 1999, p.11); (b) "The original position may be viewed, then, as a procedural interpretation of Kant's conception of autonomy and the categorical imperative within the framework of an empirical theory" (Rawls 1999, p.226. Ênfase acrescentada). A interpretação que se pretende ofertar é a de que, mediante o estratagema da posição original, Rawls estaria a impor à regra de ouro as limitações que Kant apontou serem necessárias para torná-la derivável do imperativo categórico, muito embora o próprio Kant não as tenha declinado. No caso de Rawls, tais limitações seriam aquelas do véu de ignorância. Desse modo, a razão do egoísta racional, ou como Rawls nomina, do desinteressado no bem dos outros, ${ }^{2}$ que é aquela operante na posição original, tem que gerar um conteúdo cuja perspectiva de cumprimento na sociedade não pode ser a do egoísta, mas tem que ser cumprida pelas razões corretas, posto que, caso fosse cumprida pelo autointeresse ilustrado, seria um modus vivendi, o que tornaria a sociedade instável (Rawls 1996, p.XLI). Então, poder-se-ia perguntar: será que o conteúdo gestado a partir de uma perspectiva estratégica tem pedigree para ser cumprido sob uma perspectiva moral?

Habermas observa que aquele que raciocina na posição original não precisa descentrar a sua perspectiva para assumir o ponto de vista moral que considera o que é do interesse de todos (Habermas 2004, p.64). Na verdade, é o véu de ignorância que cria um mecanismo que força o ponto de vista do eu a coincidir com o ponto de vista de todos: "como elas [as partes na posição original] não sabem que posições ocuparão no futuro, na sociedade por elas ordenada, seu próprio interesse leva-as a pensar a respeito do que seja uniformemente bom para todos" (2004, p.64). Melhor dito,

The Rawlsian 'veil of ignorance' forces rational individuals to make moral choices. That is, although individuals in Rawls' idealized decision situation, which Rawls calls the 'original position', do not have to be moral beings, the moral ideals that Rawls wants to be expressed by the principles of justice to be derived in the original position are enforced by the structure of his hypothetical decision situation' (Moehler 2011, p.13).

Essa seria a construção que moldaria a escolha racional de uma maneira razoável. É assim que o ponto de vista moral é operacionalizado, ou seja, é como o im- 
perativo categórico é vertido em uma formulação hipotética. Contudo, coteja ele, as partes, pelo seu egoísmo racional, não podem tomar a perspectiva pela qual os que elas representam deverão agir (Habermas 2004, pp.65-6). Porém, se os representados assim não o fizerem, constituir-se-á tão somente uma ordem social segundo um modus vivendi, o que levaria à instabilidade, dentre outras fatores, pelo recalcitrante problema do free-rider (Habermas 2004, p.80). Finalmente, segundo Habermas, o sentido deontológico dos princípios de justiça que as partes buscam, pressupõe competências cognitivas que vão além daquelas das pessoas que escolhem racionalmente de forma cega para tais determinações normativas (Habermas 2004, p.66). Qual seria o mencionado sentido deontológico? Justamente o ponto de vista do que é bom para todos, que os situados na posição original não têm porque operam a partir do que é bom para o seu eu, ainda que sob o véu de ignorância. Com isso, Habermas se compromete a dizer um caso de um dever no qual o interesse bem compreendido de cada um não estaria preservado. Vale lembrar, nesse particular, a crítica de Schopenhauer segundo a qual a ética kantiana seria um egoísmo racional, justamente porque os deveres responderiam por interesses bem compreendidos dos indivíduos.

Ora, acusa Habermas, dar ao procedimento da posição original um viés egocêntrico é inadequado, pois não opera uma verdadeira perspectiva que representaria o ponto de vista de todos (Habermas 2004, p.71). Com isso, claro, Habermas quer defender que o procedimento por ele proposto, argumentativamente concebido, realiza melhor o que demanda o imperativo categórico. Considerando o pluralismo que o próprio Rawls toma por base de sua teoria, como pode o eu pensar no igual interesse de todos? Rawls pretende impor uma perspectiva comum (Habermas 2004, pp.70-1) pela ignorância da posição pessoal que cada um ocupará na sociedade, ao passo que a ética discursiva apelará para a argumentação.

Ademais, ele sustenta que as limitações à regra de ouro ou à racionalidade estratégica que opera a partir de primeira pessoa, para que seja compatível com o imperativo categórico, porta natureza substantiva (Habermas 1995). Certamente, é justificada a ignorância da religião, da classe social, do sexo, da cor da pele, mas por que não também a ignorância da beleza, já que isso afeta a autoestima que é um bem primário, do ser nascido ou não, pois isso teria efeito sobre o aborto, dos talentos genéticos, já que isso tem efeito sobre políticas de eugenia, do país ao qual se pertence, pois as fronteiras nas quais se nasce determinam profundamente as condições para a felicidade de alguém, etc. Nesse sentido, observa Habermas, o ponto central da justificação dos princípios de justiça é menos a deliberação na posição original e mais a justificação das intuições do que compõe a própria posição original. Isso ocorre porque a posição original é um procedimento prenhe de conteúdo normativo que precisa ser justificado, como o conceito de pessoa que deve ter um senso de justiça e ter a capacidade para escolher uma concepção de bem (2004, p.73). Isso soa como o predicado da 
autoconservação que tem que ser pressuposto por Hobbes para que se sigam as leis naturais.

\section{Aplicação do imperativo categórico e da regra de ouro}

Como já mencionado, Kant critica a regra de ouro quando ela é considerada sem limitações, circunstância na qual ela não teria o condão de fundamentar qualquer dever. Sem embargo dessa proposição, ele faz ao menos duas afirmações que merecem consideração. A primeira já foi mencionada, a saber, a de que com várias limitações a regra de ouro poderia ser pensada como sendo derivável do imperativo categórico: "Pois ele é, se bem que com diversas restrições, tão-somente derivado daquele". Ora, se ela é derivável do imperativo categórico, então, pode-se considerar que alguns elementos que compõem a regra de ouro estão também presentes no imperativo categórico. Ou seja, pode haver semelhanças entre os dois princípios, já que com várias limitações a regra de ouro seria derivável do imperativo categórico. A interpretação de Rawls aqui proposta é a de que ele apresentaria quais poderiam ser as limitações sugeridas por Kant em relação à regra de ouro para torná-la uma versão do imperativo categórico. Não obstante, se pretende aqui fazer o caminho inverso do sugerido nessa interpretação e analisar que possíveis elementos da regra de ouro poderiam ser encontrados no imperativo categórico ou pelo menos quais seriam passíveis de serem atribuídos ao imperativo categórico. A hipótese é a de a operacionalização do imperativo categórico feita por Kant, ou seja, a sua aplicação, toma uma forma egocêntrica ou monológica, a qual seria própria da regra de ouro. É sobre esse ponto preciso que Habermas se manifesta: "Como uma praxe legislativa só pode ser exercida em comum, não é mais suficiente a regra de ouro do uso monológico e egocêntrico desses testes de generalização" (Habermas 2004, p.44). Segundo ele, o imperativo categórico, certamente, vai além do caráter egocêntrico da regra de ouro, mas a maneira como Kant o aplicou ainda traz marcas próprias da regra de ouro, como a sua formulação sob o ponto de vista de uma lei universal da natureza. Ou seja, Habermas pretende ofertar uma formulação melhor do que aquela que o próprio Kant deu da intuição básica do imperativo categórico, qual seja, da universalidade que deve abranger o ponto e vista de todos. O imperativo categórico, sabidamente, é reformulado por Habermas nos termos de sua ética discursiva (1989), segundo a qual a aceitabilidade (Zustimmung) dos conteúdos normativos e proposicionais significa um consenso (Einverstandnis) que tem que ser motivado por razões declinadas em um discurso argumentativo. A aceitabilidade não pode ser entendida como um contrato (Vereinbarung) motivado pela perspectiva egocêntrica de cada um (2004, p.56).

Portanto, se o imperativo categórico for operacionalizado de forma monológica, ele se aproximará do caráter egocêntrico da regra de outro (Habermas 2004, pp.70-

Principia 20(3): 377-392 (2016). 
1). De fato, pode-se dizer que Kant operacionaliza o imperativo categórico de uma forma monológica em contraposição a uma forma dialógica. Tal pode ser percebido nos problemas suscitados pela aplicação do mesmo feita por Kant na Fundamentação. Destarte, se forem consideradas as aplicações que Kant fez imperativo categórico pode-se verificar que elas dependem de premissas que poderiam ser nominadas limitações, ou seja, são hipóteses ad hoc introduzidas para que a fórmula possa funcionar. Tais hipóteses ad doc têm que ser introduzidas para que a operacionalização egocêntrica ou monológica do imperativo categórico possa funcionar, de tal forma que o raciocínio só pode operar do modo esperado com premissas adicionais. Senão vejam-se os exemplos de Kant.

O suicídio. Na fórmula da lei da natureza, o resultado esperado, qual seja, a interdição do suicídio, depende da existência no indivíduo de uma "sensação que nos foi destinada para impelir à promoção da vida" (Kant 2009, p.422), pois a contradição só surge se por causa desse sentimento alguém escolhesse a máxima de se suicidar, pois tal sentimento teria uma outra finalidade. A contradição do suicídio depende, portanto, de uma consideração metafísica da natureza do homem, ou seja da finalidade de um sentimento que o constituiria. Metafísica aqui deve ser entendida no sentido criticado pela Crítica da razão pura. No que concerne à fórmula da humanidade como um fim em si mesma aplicada a esse caso, ela, certamente, tem conteúdo inderrogável, porém, a operacionalização solitária ou monológica feita por Kant mostra como tal conteúdo pode ser saturado de forma não aceitável. Seguramente, se for considerada a discussão hodierna sobre a eutanásia [indireta e passiva ${ }^{3}$ ], a distanásia e a ortotanásia, ${ }^{4}$ o mínimo que se pode dizer é que o valor da vida humana não pode ser medido pelo modo como Kant mediu, de tal forma que a evolução discursiva sobre a matéria é que pode melhor lhe dar os contornos morais substantivos, e não um cálculo egocêntrico, o qual se encontra mais sujeito às vicissitudes da parcialidade e aos vícios do tempo presente do que uma versão dialógica.

Os TALENTOS. Na fórmula da natureza, Kant precisa definir substantivamente o que é racionalidade para que o resultado esperado ocorra, qual seja, o dever de desenvolver os próprios talentos. Por operar egocentricamente, se o sujeito não fosse definido por certas determinações apropriadas, o raciocínio não funcionaria. Por isso, Kant tem que sustentar que um ser racional que quer fins tem que querer o desenvolvimento de seus talentos: "enquanto ser racional, ele quer necessariamente que todas as faculdades sejam desenvolvidas nele, porque lhe são úteis estão dadas para toda espécie de fins possíveis" (Kant 2009, p.423). Caso contrário, não haveria contradição do querer. Não obstante, a preguiça não tem nada de irracional, nem seria irracional um mundo com menos opções de escolha. Por seu turno, de acordo com a fórmula da humanidade, o resultado esperado depende da seguinte definição da humanidade: "há no homem predisposições naturais a uma maior perfeição, que pertencem ao fim da natureza com respeito à humanidade em nosso sujeito" (2009, p.430). 
A AJUDA. Segundo a fórmula da natureza, a contradição da vontade consigo mesma depende de uma premissa empírica problemática, qual seja, a de querer ajuda: "esperança do auxílio que deseja para si" (Kant 2009, p.423). No entanto, amiúde, podem-se contar muitos casos de pessoas que não querem ser ajudadas e mesmo pode-se contar as que querem ajuda para morrer, o que, aliás, conflita com o dever de não se suicidar. O próprio Kant admite não haver, em si mesmo, nenhuma inconsistência em um mundo sem ajuda mútua. Já, de acordo com a fórmula da humanidade, não é evidente que para o fim de um outro ter efeito em alguém, ele deva tomá-lo também como seu fim: "Pois os fins do sujeito que é fim em si mesmo têm de ser também, tanto quanto possível, os meus fins, se aquela representação deve produzir em mim todo 〈o seu〉 efeito" (Kant 2009, p.430). Com relação à última parte da citação, aquela com relação a um efeito completo dos fins de uma pessoa em outra, pode-se perguntar por que deveria ter um efeito completo? Por que se deve ir além do efeito daquele que respeita os fins dos outros, sem interferir, mas também sem ajudar? Kant não fornece nenhum argumento para a completude do efeito mencionado. Ainda mais, pode-se partir de uma concepção completamente diferente de ser humano, como aquela de Rawls, citada acima, segundo a qual as partes não só não têm interesse nos fins dos outros, como podem ter objetivos espirituais opostos, e, ainda assim, ser possível fundamentar deveres de ajuda, como aqueles decorrentes do segundo princípio de justiça.

A PROMESSA. Na fórmula da natureza, a promessa parece ser o único exemplo cuja contradição residiria nos próprios termos da máxima de não cumprir as promessas, sem premissas adicionais. Contudo, pode-se verificar por meio de outras considerações sobre a promessa que a simples inconsistência não é um motivo para tornar dever todas as promessas. Rawls e Dworkin podem ser considerados como exemplares de tratamento da promessa, cuja justificação não remete à inconsistência ou não remete somente à inconsistência. Hobbes também considerou haver promessas nulas, apesar da contradição que estaria envolvida no não cumprimento de uma promessa, o que ele visionariamente chamou a atenção no De cive, obra, aliás, que Kant conhecia muito bem, tanto que a cita no texto Contra Hobbes.

Para Rawls, a prática da promessa, tão importante para Kant, não é matéria moral, mas uma prática convencional:

It is not itself a moral principle but a constitutive convention. In this respect it is on a par with legal rules and statutes, and rules of games; as these do, it exists in a society when it is more or less regularly acted upon. The way in which the rule of promising specifies the appropriate circumstances and excusing conditions determines whether the practice it represents is just (Rawls 1999, p.303).

Trata-se de uma prática que se constitui em um meio racional para estabilizar os acordos de cooperação para a vantagem comum. Em razão de a promessa ser uma 
instituição determinada por critérios públicos e jurídicos, os princípios de justiça se aplicam a ela, assim como se aplicam a qualquer outra instituição pública, cujo principal mote é manter a liberdade igual, de tal forma que a obrigação não decorre da promessa enquanto tal, mas da justiça que deve estar na sua base: "Even the rule of promising does not give rise to a moral obligation by itself. To account for fiduciary obligations we must take the principle of fairness as a premise" (Rawls 1999, p.306).

Dworkin, por sua vez, argumenta que a quebra de uma promessa sempre causa dano, se considerada em si mesma, pois solapa a base a partir da qual se delibera (2011, p.305). Porém, há muitos outros fatores a serem considerados, como as circunstâncias daquele que faz a promessa e a relevância das suas escusas, de tal forma que a promessa tem que ser analisada sob o ponto de vista da sua convencionalidade (Dworkin 2011, p.309), ou seja, "promising is not a self-contained practice that generates obligations automatically, but is instead parasitic on the much more general duty not to harm others" (Dworkin 2011, p.310). Por isso, a promessa depende de interpretação, de tal forma a se levar em consideração o conjunto das obrigações morais. Por exemplo, levar alguém para um hospital deve ser aceito como uma escusa para não cumprir uma promessa de comparecer a um jantar, de tal forma que ela não é absoluta, ou seja, não deve ser considerada a partir da clausura de seus próprios termos. Mais que isso, Dworkin alega não haver uma métrica criterial objetiva para determinar o valor da promessa feita, ou seja, não há "an algorithm for testing promises and their breach. We can only say that we must assign a high level of seriousness to promises- but not too high — when we draw our judgments about promise - keeping from, and integrate them with, our other and more general convictions about not harming people" (Dworkin 2011, p.311). Dworkin parece mesmo aceitar uma das teses de Constant que Kant recusou, qual seja, uma sociedade que vivesse com base na estrita promessa seria impossível. Por isso mesmo, seria necessário o estabelecimento de critérios intermediários.

Como já mencionado, e por ser pertinente ao assunto, é de se observar que a noção de uma contradição da vontade já está presente na formulação que Hobbes faz das leis de natureza. Segundo ele, querer viver em um estado de guerra, que é o contrário da máxima da paz, implicaria uma contradição consigo mesmo. Contudo, depreende-se da leitura do texto que a contradição é gerada sob a pressuposição de que haja o desejo do próprio bem:

The estate of hostility and war being such, as thereby nature itself is destroyed, and men kill one another [...] he therefore that desireth to live in such an estate, as is the estate of liberty and right of all to all, contradicteth himself. For every man by natural necessity desireth his own good, to which this estate is contrary, wherein we suppose contention between men by nature equal, and able to destroy one another (Hobbes 1928, §12).

Pelo próprio bem se deve entender a própria segurança e preservação (Hobbes Principia 20(3): 377-392 (2016). 
$1928, \S 13)$. Interessante anotar que as formulações do imperativo categórico de Kant têm a mesma estrutura de um imperativo hipotético em Hobbes. Ou seja, a contradição da vontade, para Hobbes, só é gerada sob o pressuposto de a pessoa querer seu próprio bem, sua própria segurança e sua conservação. Caso contrário não haveria contradição. Como se pode verificar, a mesma estrutura se repete nos exemplos de Kant, com exceção da promessa, a qual parece ser uma contradição nos próprios termos, sem premissas adicionais.

Por seu turno, os trabalhos de Hegel sugerem que mesmo a promessa tem conteúdo pressupostos para que possa haver contradição. Para Hegel, a universalidade é puramente uma unidade analítica, uma tautologia, de tal forma que pode ser agregada a qualquer conteúdo (Hegel 2004, p. 123). Nesse mesmo diapasão, uma das análises principais que Hare faz da universalização é a de que ela se constitui em uma tese lógica despida de substância moral: "it is a logical thesis and not a substantive moral principle" (1965, p.34). Na sua análise, portanto, a substância moral deve ser diferenciada da forma lógica da univesalidade: "It is very important not to confuse the thesis of universalizability with the substantial moral principles to which, according to it, a person who makes a moral judgement commits himself" (1965, p.30).

Toda máxima, segundo Hegel, tem um conteúdo (2004, p.123). Nesse sentido, afirma ele, caso não existisse propriedade, qualquer coisa que pretendesse ser propriedade seria anulada [aufgehoben], o que não deixa de ser o caso quando se está no estado de natureza. Nesse sentido, Hegel chama a atenção para o fato de a argumentação da promessa em Kant estar completamente atrelada ao depósito. Na Fundamentação, o exemplo que Kant fornece é o de pedir dinheiro emprestado. No final de seu argumento, ele conclui que fazer uma promessa sem a intenção de cumprir tornaria impossível a promessa e o fim que com ela se pretende (Kant 2009, p.422). Contudo, a citação que Hegel faz no seu texto é aquela da Crítica da razão prática, segundo a qual se a máxima mencionada se tornasse lei, "faria com que não existisse absolutamente depósito algum" (Kant 2002, p.93). Não obstante, afirma Hegel, que contradição haveria no mundo se não houvesse depósitos (2004, p.125). Não há contradição em pensar uma sociedade sem depósito. Nesse diapasão é que se pode compreender a argumentação de Rawls no sentido de uma casuística da validade das promessas. Portanto, as promessas valem quando se têm em vista promessas específicas, sendo que os casos mais importantes são objeto de contrato. É desse modo que se entende que a promessa de algo que não faz sentido para a sociedade, não tem valor algum, como alguém prometer que jamais pedirá demissão de seu emprego ou prometer, caso não pague uma dívida, ser reduzido à condição de escravo por um período determinado de tempo.

Por fim, vale ainda observar que, a despeito de a fórmula da humanidade ser um conteúdo inderrogável para a universalidade do imperativo categórico, quando com- 
parada com outros seres vivos, ela é especista a não mais poder. ${ }^{5}$ Por derradeiro, ad argumentandum tantum, como ficaria o aborto em relação ao imperativo categórico, vis-à-vis da afirmação kantiana de que "conservar a minha vida é um dever condicional (se isso pode ocorrer sem crime); mas é um dever incondicional não a tirar a outrem, que não me prejudicou, e que nem sequer me põe em perigo de perder a minha" (Kant 1988, p.300)? Com relação a esse ponto, aliás, é de se registrar o que ele afirma no §28 da Doutrina do direito, sobre o direito dos progenitores. Para ele é necessário considerar "o ato de procriação como aquele mediante o qual pusemos uma pessoa no mundo, sem o seu consentimento [...] Não podem [os pais] destruir o seu filho como se fora um artefato por si produzido" (Kant 2005, p.281). Ou seja, "aquilo que foi produzido é uma pessoa" (Kant 2005, p.280). Obviamente, Kant não se manifesta em qual momento ocorreria a marca da pessoalidade, embora pareça sugerir a concepção, valendo registrar, entretanto, que ele é totalmente favorável à pena diminuída ou mesmo à ausência de pena com relação ao infanticídio, quando a criança foi concebida fora do casamento.

Tudo isso apenas para mostrar a problematicidade do modo monológico ou egocêntrico de aplicar o imperativo categórico. Aliás, quiçá, seja essa formulação monológica a explicar objeções a Kant e defesas dele que se fizeram necessárias ao longo da história. Mill, por exemplo, baseado no termo querer que aparece na fórmula do imperativo categórico, sustenta:

But when he [Kant] begins to deduce from this precept [categorical imperative] any of the actual duties of morality, he fails, almost grotesquely, to show that there would be any contradiction, any logical (not to say physical) impossibility, in the adoption by all rational beings of the most outrageously immoral rules of conduct. All he shows is that the consequences of their universal adoption would be such as no one would choose to incur. (Mill 2003, p.183)

Schopenhauer foi bem mais explícito em relação a esse ponto:

[...] its [categorical imperative] basis turns out to be nothing else than Egoism, the latter being the secret interpreter of the direction which it contains. Furthermore, regarding it solely as a formula, we find that it is only a periphrasis, an obscure and disguised mode of expressing the well-known rule: Quod tibi fieri non vis, alteri ne feceris (1915, pp.86-7).

Certamente, o kantismo tem recursos para se defender dessas acusações. Por exemplo, Gregor, ao tratar desse assunto, registrou que o uso de determinações teleológicas da natureza que devem operar para que a fórmula do imperativo categórico como lei da natureza possa funcionar sugere que Kant estaria transpondo os limites da filosofia crítica: "The liberal use which Kant makes of natural teleology does not mean that he has thrown his Critical caution to the winds" (Gregor 1963, p.132); 
continua ela, "But the teleological principle is a subjective one in the sense that it tells us nothing about objects of experience themselves" (p.133). Sem embargo disso, ela mesma observa que tais determinações podem ser depuradas para que se manifeste o argumento propriamente dito: "[...] the teleological considerations add nothing to the argument itself" (p.138). ${ }^{6}$ Nesse diapasão, Kant teria usado de uma espécie de senso comum moral de base estóica vigente à época: "This study suggests that it was the popular Stoic formula convenienter naturae vivere which gave Kant his clue that the notion of a law of nature could be used to represent the moral law" (Gregor 1963, p.145). No entanto, o cerne do argumento, não residiria nem em uma inconsistência teleológica nem uma inconsistência lógica, mas em uma consistência teleológica entre as máximas e os fins racionais objetivos. ${ }^{7}$

Ademais, quando Kant se pronuncia sobre o jus necessitatis na Doutrina do direito e em Contra Hobbes, o viés propriamente deontológico de sua teoria, portanto não consequencialista ou egoísta, aparece com toda clareza: "Pois conservar a minha vida é apenas um dever condicional (se tal puder ocorrer sem crime); mas é um dever incondicional não a tirar a outrem, que não me prejudica, e que nem sequer me põe em perigo de perder a minha" (Kant 1793, pp.31-2).

\section{Conclusões}

Habermas é um crítico do contratualismo por considerar que ele não realiza com a acurácia necessária as intuições fundamentais do ponto de vista moral que deve considerar de forma igual o interesse de todos.

Pode-se dizer que boa parte de sua crítica tem como pano de fundo a regra de ouro ou formulações que poderiam ser aproximadas da regra de ouro. O problema dessa estratégia de fundamentação da ordem social e do direito é que ela opera a partir de uma perspectiva egocêntrica da primeira pessoa. Alega ele ser impossível encontrar em tal formulação os elementos cognitivos necessários para dar conta das determinações normativas fundamentais para a moral, o direito e a justiça.

No caso de Hobbes, o tipo de razão moral necessária para fundamentar as leis naturais estaria contido na regra de ouro. Desse modo, Habermas faz duas alegações contra Hobbes. A primeira é a de que o seu arcabouço teórico depende de premissas morais que deveriam ser supostamente fornecidas pela regra de ouro, mas que de fato não são fornecidas. Por isso, o sistema de Hobbes só aparentemente operaria a partir da racionalidade estratégica. A segunda é a que a regra de ouro não conseguiria fornecer o que Hobbes necessitaria, porque o que ele necessita estaria em contradição com a perspectiva do egoísta racional que está na base de compreensão da regra de ouro.

No caso de Rawls, o problema é semelhante, pois Rawls pretende deduzir da

Principia 20(3): 377-392 (2016). 
posição original os conteúdos igualitários da justiça. Contudo, as partes, sob o véu de ignorância da posição original, raciocinam a partir de seus próprios interesses. Segundo Habermas, haveria uma falta de sincronia entre o ponto de vista dos representados que têm de poder obedecer as regras de justiça pelas razões corretas, não só como um modus vivendi, sob pena de instabilidade da sociedade assim estruturada, e o ponto de vista dos representantes na posição original que operam a partir do seu próprio interesse.

Por fim, Habermas sugere que a sua teoria discursiva, com base na argumentação, estaria melhor equipada para realizar as intuições do ponto de vista moral.

\section{Referências}

CFM. Resolução CFM no 1931/2009. (Publicada no D.O.U. de 24 de setembro de 2009, Seção I, p. 90) (Retificação publicada no D.O.U. de 13 de outubro de 2009, Seção I, p.173). Aprova o Código de Ética Médica.

Dworkin, R. 2011. Justice for Hedgehogs. Cambridge: Harvard University Press.

Gregor, M. J. 1963. Law of Freedom: A Study of Kant's Method of Applying the Categorical Imperative in the 'Methapysik der Sitten'. Oxford: Blackwell.

Habermas, J. 1971 [1968]. Theorie und praxis. Suhrkamp: Frankfurt am Main.

—. 1989. Consciência moral e agir comunicativo. Trad. Guido A. de Almeida. Rio de Janeiro: Tempo Brasileiro.

- 1994. Faktizität und Geltung: Beiträge zur Diskurstheorie des Rechts und des demokratischen Rechtsstaats. 4. Auflage, Frankfurt am Main: Suhrkamp.

- 1995. Reconciliation through the Public Use of Reason: Remarks on John Rawl's Political Liberalism. The Journal of Philosophy 92(3): 109-31.

-1997a. Direito e democracia: entre faticidade e validade. [v. I]. Trad. F. B. Siebeneichler. Rio de Janeiro: Tempo Brasileiro.

—. 1997b. Direito e democracia: entre faticidade e validade. [v. II]. Trad. F. B. Siebeneichler. Rio de Janeiro: Tempo Brasileiro.

- 1998[1996]. The Inclusion of the Other: Studies in Political Theory. Transl. Ciaran Cronin. Cambridge: MIT Press.

- 2004. A inclusão do outro: estudos de teoria política. Trad. G. Sperber, P. A. Soethe, M. C. Mota. 2. ed., São Paulo: Loyola.

Hegel, G. W. F. 2004. On the Scientific Ways of Treating Natural Law, on its Place in Practical Philosophy, and its Relation to the Positive Sciences of Right (1802-1803). In: G. W. F. Hegel. Political Writings. Org. by Laurence Dickey and H. B. Nisbet. Tansl. by H. B. Nisbet. Cambridge: Cambridge University Press, pp.102-180.

Hobbes, T. 1983[1642]. De Cive. Oxford: Clarendon.

-1928[1640]. The Elements of Law Natural and Politic. Cambridge: Cambridge University Press.

Kant, I. 1793. Sobre a expressão corrente: isso pode ser correcto na teoria, mas nada vale na prática. Trad. Artur Morão. Covilhã: Lusofia Press.

—. 1988. A paz perpétua e outros opúsculos. Trad. A. Morão. Lisboa: E. 70.

Principia 20(3): 377-392 (2016). 
- 2002. Crítica da razão prática. Trad. Valério Rohden. São Paulo: Martins Fontes.

- 2005. A metafísica dos costumes. Tr. J. Lamego. Lisboa: Fundação Calouste Gulbenkian.

- 2009. Fundamentação da metafísica dos costumes. Trad. G. A. de Almeida. São Paulo: Discurso Editorial/Barcarolla.

Mill, J. S. 2003. Utilitarianism and On Liberty. Including Mill's 'Essay on Bentham' and selections from the writings of Jeremy Bentham and John Austin. [Ed. with an Introduction by Mary Warnock]. 2. ed. Oxford : Blackwell.

Moehler, M. 2011. A Hobbesian Derivation of the Principle of Universalization. Philosophical Studies 158(1): 83-107.

Nagel, T. 1959. Hobbes's Concept of Obligation. Philosophical Review. 68: 68-83.

Rawls, J. 1985. Justice as Fairness: Political not Metaphysical. Philosophy and Public Affairs. 14(3): 223-251.

—. 1996[1993]. Political Liberalism. New York: Columbia University Press.

- 1999[1971]. A Theory of Justice. [Revised Edition]. Oxford: Oxford University Press.

- 2007. Lectures on the History of Political Philosophy. Cambridge, MA: Harvard University Press.

Singer, P. 1993. Practical Ethics 2. ed., Cambridge: Cambridge University Press.

Schopenhauer, A. 1915[1840]. The Basis of Morality. Trans. A. B. Bullock. 2. ed. London: George Allen.

Volpato Dutra, D. J. 2002. Kant e Habermas: a reformulação discursiva da moral kantiana. Porto Alegre: EDIPUCRS.

Warrender, H. 1957. The Political Philosophy of Hobbes. Oxford: Oxford University Press.

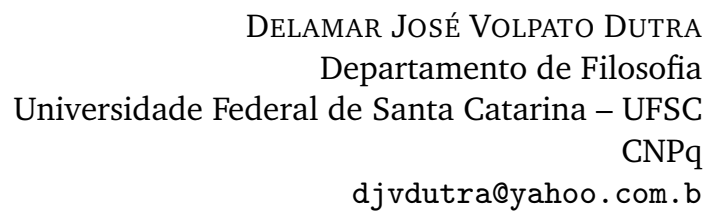

\section{Notas}

1 "What Kant must mean is that, to be reasonable, the criminal must assess the judge's action by reasoning in accordance with the CI-procedure and not in terms of the criminal's own situation and desire not to be punished. What is wrong with the Golden Rule (in both its positive and negative versions) is that as stated it allows our natural inclinations and the special circumstances to play an improper role in our deliberations. But in saying this Kant implies that the CI-procedure specifies their proper role" (Rawls 2000, p.199).

2 "One feature of justice as fairness is to think of the parties in the initial situation as rational and mutually disinterested. This does not mean that the parties are egoists, that is, individuals with only certain kinds of interests, say in wealth, prestige, and domination. But they are conceived as not taking an interest in one another's interests. They are to presume that even their spiritual aims may be opposed, in the way that the aims of those of different religions may be opposed. Moreover, the concept of rationality must be interpreted as far as possible

Principia 20(3): 377-392 (2016). 
in the narrow sense, standard in economic theory, of taking the most effective means to given ends" (Rawls 1999[1971], §3, p.12). Mesmo em Hobbes, o que o homem busca é assegurar a sua vida. Se os outros puderem assegurar as suas concomitantemente não é um problema para ele. Com bem observa Rawls, o problema que tem ser resolvido na posição original ou no estado de natureza não é um jogo de soma zero (Rawls 1999[1971], §42, p.238, nota 8). É por isso exatamente que a justiça só é possível quando a escassez econômica for moderada. Porque se ela for severa, será um jogo de soma zero, quando então não é possível haver um equilíbrio de Nash, não sendo, portanto, possível a justiça.

${ }^{3}$ Pode ser considerada passiva quando o processo de morte começa pela abstenção de tratamento. Pode ser considerada ativa quando ela resulta de efeito colateral de tratamento paliativo de cuidado.

${ }^{4} \mathrm{~A}$ ortotanásia foi regulada no Brasil pelo Código de ética médica, vis-à-vis do parágrafo único do art. 41: "Parágrafo único. Nos casos de doença incurável e terminal, deve o médico oferecer todos os cuidados paliativos disponíveis sem empreender ações diagnósticas ou terapêuticas inúteis ou obstinadas, levando sempre em consideração a vontade expressa do paciente ou, na sua impossibilidade, a de seu representante legal" [CFM. Resolução CFM $N^{o}$ 1931/2009. (Publicada no D.O.U. de 24 de setembro de 2009, Seção I, p. 90) (Retificação publicada no D.O.U. de 13 de outubro de 2009, Seção I, p.173). Aprova o Código de Ética Médica].

${ }^{5}$ O termo especismo [speciesism] foi criado por Richard D. Ryder em 1970 [Singer, Peter (ed.) In Defense of Animals: A Second Wave. Oxford: Blackwell, 2006, p.IX], o qual pode ser definido do modo seguinte: "Speciesism is, in brief, the idea that it is justifiable to give preference to beings simply on the grounds that they are members of the species Homo sapiens" [Singer, Peter (ed.) In Defense of Animals: A Second Wave. Oxford: Blackwell, 2006, p.3]. Ver a esse respeito também Singer1993, p.62s.

6 "Kant distinguishes clearly between our view that an action is 'unnatural' and the 'rational' proof that the action is immoral. In connection with the principle 'live according to nature' I suggested that the unnatural character of an action is itself morally irrelevant and that 'nature' becomes morally significant only in so far as the natural use of our instincts coincides with a rational system of ends. [...] The proof in fact depends not on any special attribute of nature, but on the relation of a maxim to the order which a fully rational being would necessarily institute among the ends of his composite being. [...] the criteria drawn from 'nature' belong only to the exposition, not to the discovery, of what constitutes our duty. [...] It can simply be removed without affecting the 'rational proof' itself." (Gregor 1963, pp.133-134).

7 "But Kant's own derivation of duties shows clearly that he is not thinking of logical consistency as the criterion of moral action. The freedom from contradiction which he requires in a universalized maxim is, rather, a teleological consistency between our maxim and our objective, rational ends. Thus in Kant's own account of suicide it is not the self-defeating character of the maxim that makes it immoral. It is rather the fact that, in acting on a maxim of arbitrarily destroying our capacity for free or moral action, we are in contradiction with our objective end as free or moral agents, and so in contradiction with ourselves." (Gregor 1963, p.203).

Principia 20(3): 377-392 (2016). 